\title{
Dynamic Interactions between Top-Down Expectations and Conscious Awareness
}

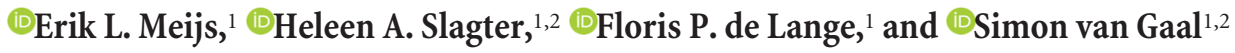 \\ ${ }^{1}$ Donders Institute for Brain, Cognition and Behaviour, Radboud University and Radboud University Medical Center, 6500 HB Nijmegen, The Netherlands, \\ ${ }^{2}$ Department of Psychology, and ${ }^{3}$ Amsterdam Brain and Cognition Centre, University of Amsterdam, 1001 NK Amsterdam, The Netherlands
}

It is well known that top- down expectations affect perceptual processes. Yet, remarkably little is known about the relationship between expectations and conscious awareness. We address three crucial outstanding questions: (1) how do expectations affect the likelihood of conscious stimulus perception?; (2) does the brain register violations of expectations nonconsciously?; and (3) do expectations need to be conscious to influence perceptual decisions? Using human participants, we performed three experiments in which we manipulated stimulus predictability within the attentional blink paradigm, while combining visual psychophysics with electrophysiological recordings. We found that valid stimulus expectations increase the likelihood of conscious access of stimuli. Furthermore, our findings suggest a clear dissociation in the interaction between expectations and consciousness: conscious awareness seems crucial for the implementation of top- down expectations, but not for the generation of bottom-up stimulus-evoked prediction errors. These results constrain and update influential theories about the role of consciousness in the predictive brain.

Key words: attentional blink; consciousness; electroencephalography; expectation; visual perception

\section{Significance Statement}

While the relationship between expectations and conscious awareness plays a major role in many prediction-based theories of brain functioning, thus far few empirical studies have examined this relationship. Here, we address this gap in knowledge in a set of three experiments. Our results suggest that the effect of expectations on conscious awareness varies between different steps of the hierarchy of predictive processing. While the active use of top-down expectations for perceptual decisions requires conscious awareness, prediction errors can be triggered outside of conscious awareness. These results constrain and update influential theories about the role of consciousness in the predictive brain.

\section{Introduction}

A rapidly growing body of work indicates that sensory processing is strongly influenced by expectations we have about likely states of the world. Such expectations are shaped by the context in which we are operating, but also by learning, experience, and our genetic makeup (Friston, 2005; Bar, 2009; Summerfield and de Lange, 2014). Expectations are typically thought to originate

\footnotetext{
Received July 10, 2017; revised Nov. 9, 2017; accepted Nov. 26, 2017.

Author contributions: E.L.M., H.A.S., F.P.d.L., and S.v.G. designed research; E.L.M. performed research; E.L.M., H.A.S., F.P.d.L., and S.v.G. analyzed data; E.L.M., H.A.S., F.P.d.L., and S.v.G. wrote the paper.

The authors declare no competing financial interests.

This work was supported by the Netherlands Organization for Scientific Research (NWO VENI 451-11-007 awarded to S.v.G.; NWO VIDI 452-13-016 awarded to F.P.d.L.), the European Research Council (ERC-2015STG_679399 awarded to H.A.S.) and the James S. McDonnell Foundation (Understanding Human Cognition, 220020373, awarded to F.d.L.). We thank Doris Dijksterhuis, Sjoerd Manger, and Thomas Dolman for their valuable assistance with data acquisition. We thank Timo Stein and Josipa Alilovic for valuable comments on a previous draft of this manuscript.

Correspondence should be addressed to Simon van Gaal, University of Amsterdam, Department of Psychology, 1001 NK Amsterdam, the Netherlands. E-mail: simonvangaal@gmail.com.

DOI:10.1523/JNEUROSCI.1952-17.2017

Copyright $\odot 2018$ the authors $\quad 0270-6474 / 18 / 382318-10 \$ 15.00 / 0$
}

from higher-level brain regions, such as the (pre)frontal cortex, which may guide information processing in lower-level sensory regions via top-down projections. In this framework, what we consciously see is proposed to be strongly influenced by the brain's expectations about, or its best guess of, the outside world (Gregory, 1980; Hohwy, 2012; Panichello et al., 2012). Initial studies support the idea that the brain uses information in the environment to build expectations of stimulus frequency or conditional probabilities to modify perceptual processing (Bar, 2004; Kok et al., 2012). These ideas have been formalized in theoretical models, such as predictive coding and sequential sampling models (Friston, 2005; Ratcliff and McKoon, 2008; Clark, 2013). Although these frameworks are attractive in their simplicity, how exactly expectations shape conscious perception and to what extent awareness guides the formation of expectations are still largely unknown.

At present, there are at least three issues that need to be resolved to further our understanding of the relationship between expectations and consciousness. The first issue relates to the effect that expectations may have on conscious awareness itself. It has been shown that valid expectations increase the speed of con- 
scious access (Melloni et al., 2011; Pinto et al., 2015; Stein and Peelen, 2015; De Loof et al., 2016) and may help in selecting or facilitating stimulus interpretation when visual input is ambiguous or noisy (Bar et al., 2006; Denison et al., 2011; Panichello et al., 2012; Chang et al., 2015; Aru et al., 2016). It is yet an open question whether expectations can boost an otherwise unseen stimulus into conscious awareness, thereby enabling the switch from a nonconscious to a conscious stimulus representation, instead of merely facilitating its cognitive interpretation or making it appear sooner.

Second, it is an open question to what extent prediction errors, arising in a situation of invalid expectations, can be registered outside of conscious awareness. It has been shown that "oddball" stimuli (e.g., simple violations in auditory tone sequences) elicit early mismatch responses in electrophysiological signals: the mismatch negativity (MMN; Pöppel, 2004; Näätänen et al., 2007). Interestingly, MMNs can even be observed when attention is distracted from the tone sequences (Bekinschtein et al., 2009) or in several reduced states of consciousness, such as sleep (Ruby et al., 2008), anesthesia (Koelsch et al., 2006), and vegetative state (Bekinschtein et al., 2009). This suggests that the MMN reflects a preattentive nonconscious prediction error signal (Näätänen et al., 2001; Stefanics et al., 2011; Kimura and Takeda, 2015). However, it remains uncertain whether these signals originate in model-based comparisons of expectations to new input or merely reflect passive low-level sensory adaptation to repeated inputs (Garrido et al., 2009; Stefanics et al., 2016). The one study in which these mechanisms were dissociated in a nonconscious state showed adaptation remains operative during sleep, whereas prediction error detection disappears (Strauss et al., 2015), thus raising doubts about the notion that prediction errors may be registered nonconsciously.

The final issue concerns the role of awareness in implementing expectations. Many expectation-based models assume that expectations are implemented via top-down neural activation. Interestingly, influential theories of consciousness suggest that conscious access requires similar top-down interactions between higher-level (e.g., prefrontal) and lower-level (e.g., visual) brain regions, referred to as feedback or recurrent processing (Lamme and Roelfsema, 2000; Dehaene et al., 2006). Information that does not reach conscious access is thought to only trigger feedforward activity or local recurrent interactions between posterior brain regions. Therefore, it is unclear how nonconscious information, in the absence of feedback signals from higher-order cortical areas, could lead to the implementation of expectations.

\section{Materials and Methods}

Participants

We tested 26 participants in Experiment 1 ( 21 females; age, $19.5 \pm 1.3$ years), 85 participants in Experiment 2 (63 females; age, $22.0 \pm 3.2$ years), and 34 participants in Experiment 3 (27 females; age, $20.0 \pm 1.1$ years). All participants were right-handed and had normal or corrected-to-normal vision.

For all experiments, participants for whom the minimum number of observations was $<10$ in any condition were excluded from analysis. Additionally, for Experiment 3 (EEG), we excluded two participants due to problems with the reference electrodes. In the end, this resulted in the inclusion of 25 participants for Experiment 1 (20 females; age, $19.5 \pm 1.3$ years), 67 participants for Experiment 2 (49 females; age, $21.9 \pm 3.0$ years), and 29 participants for Experiment 3 ( 22 females; age. $20.0 \pm 1.1$ years).

The studies were approved by the local ethics committee of the University of Amsterdam and written informed consent was obtained from all participants according to the Declaration of Helsinki. Compen- sation was $€ 20$ for Experiment 1, €25 for Experiment 2, and $€ 30$ for Experiment 3, or equivalents in course credit.

\section{Materials}

All stimuli were generated using the Psychophysics Toolbox (Brainard, 1997; RRID:SCR_002881) within a Matlab environment (MathWorks, RRID:SCR_001622). Stimuli were displayed on an ASUS LCD monitor $\left(1920 \times 1080\right.$ pixels, $120 \mathrm{~Hz}, 50.9 \times 28.6 \mathrm{~cm}$ screen size, 46.3 pixels $\left./^{\circ}\right)$ on a "black" (RGB: [ $\left.\begin{array}{lll}0 & 0 & 0\end{array}\right], \pm 3 \mathrm{~cd} / \mathrm{m}^{2}$ ) background while participants were seated in a dimly lit room, $\sim 70 \mathrm{~cm}$ away from the screen.

\section{Procedure and stimuli}

Participants performed an attentional blink (AB) task (Raymond et al., 1992), in which on every trial a rapid series of visual stimuli was presented consisting of a sequence of 17 uppercase letters drawn from the alphabet but excluding the letters I, L, O, Q, U, and V. No letter appeared more than once per trial. Letters were presented at fixation in a monospaced font (font size: 40 points; corresponding to a height of $\sim 1.2^{\circ}$ ) for $92 \mathrm{~ms}$ each.

Experiment 1. Participants were instructed to detect target letters within the rapid serial visual presentation (RSVP). The first target (T1: G or $\mathrm{H}$ ) was always presented at the fifth position of the RSVP. On most trials $(80 \%)$ it was followed by a second target (T2: D or K) at Lag 2, Lag 4, or Lag 10 (respectively 183, 367, or 917 ms later). Each lag was equally likely. T1 was presented in green (RGB: $\left[\begin{array}{lll}0 & 255 & 0\end{array}\right]$ ), while T2 and the distractor letters were white (RGB: [255 255 255]; $\pm 320 \mathrm{~cd} / \mathrm{m}^{2}$ ).

Crucially, there was a predictive relationship between the two targets (Fig. 1A). Namely, in the $80 \%$ of trials where a T2 was presented, the identity of T1 (e.g., G) predicted which T2 was likely (75\%, e.g., D) or unlikely $(25 \%$, e.g., K) to appear. On the $20 \%$ remaining trials without a $\mathrm{T} 2$, a random distractor letter was presented at the T2 time point (every distractor letter was presented no more than once per trial.) The mapping of T1 and T2 was counterbalanced over participants, so that for half of the participants the most likely target combinations were G-D and $\mathrm{H}-\mathrm{K}$ while for the other half $\mathrm{G}-\mathrm{K}$ and $\mathrm{H}-\mathrm{D}$ were most likely. To be able to distinguish different lags in the absence of a T2 stimulus, four gray squares (RGB: [200 200200 ]; $\pm 188 \mathrm{~cd} / \mathrm{m}^{2}$; size: $0.35^{\circ}$; midpoint of each square centered at $1.30^{\circ}$ from fixation) were always presented around the stimulus (T2 or distractor) at the T2 time point. Participants were instructed to use the timing information this cue provided when making decisions about the presence of a T2 (only the letters D or K; all other letters were distractors).

Following a $150 \mathrm{~ms}$ blank period at the end of the RSVP, participants gave their responses. First, they indicated whether they had seen any T2 by pressing the left or right shift key on the keyboard. The mapping between the keys and the response options was randomized per trial to decouple participants' responses from the decision they had to make. Then they were asked to make a forced-choice judgment about the T2 letter (D or K) that was presented by typing in this letter. Finally, they made a similar response about the identity of T1 ( $\mathrm{G}$ or $\mathrm{H}$ ). We used long response timeout durations of $5 \mathrm{~s}$ and participants were instructed to value accuracy over response speed. The intertrial interval, as defined by the time between the last response and the onset of the stream, was $500-750 \mathrm{~ms}$.

The experiment consisted of two $1 \mathrm{~h}$ sessions on separate days within 1 week. In the first session, participants received instructions about the task and subsequently performed the task for six blocks of 75 trials (total 300 trials). The goal of the training session was to familiarize participants with the task. Besides, since we did not instruct participants about the predictive relationship between $\mathrm{T} 1$ and $\mathrm{T} 2$, some practice on the task was required for them to (implicitly) learn this relationship. In the second session, participants first received a summary of the instructions, after which the actual experiment started. Participants performed six blocks of 90 trials (total of 540 trials) of the $\mathrm{AB}$ task. The first three participants performed six blocks of 105 trials ( 630 trials). In both sessions, participants received summary feedback about their performance at the end of each block, followed by a short break.

Experiment 2 (EEG). The task in the EEG experiment was the same as in Experiment 1, except that in Experiment 2, we only asked participants to give one response by typing in the target letters they observed. In 
addition, we only used two different lags: Lag 3 (275 ms; two-thirds of trials) and Lag 10 (917 $\mathrm{ms}$; one-third of trials). To further increase the number of trials, the intertrial interval range was reduced to $200-400 \mathrm{~ms}$.

Again, the experiment consisted of two different sessions within 1 week. The first session ( $1 \mathrm{~h})$ consisted of instructions followed by extensive training (720 trials over six blocks) on the task. Participants were not explicitly informed about the predictive relationship between the targets. In the second session $(2 \mathrm{~h})$, we first prepared the participant for the EEG measurements (see below) and gave brief instructions about the task. Then, participants performed 12 blocks of 120 trials (total, 1440 trials) of the AB task.

Experiment 3. To investigate the importance of $\mathrm{T} 1$ detection for expectation effects on conscious access, we adjusted the task we used in Experiment 1 to decrease the visibility of T1 (see Fig. 4A). We now presented $\mathrm{T} 1$ in white instead of green to make it stand out less among the other stimuli. Furthermore, T1 duration was staircased per participant such that participants could report $\mathrm{T} 1$ on $\sim 75 \%$ of the trials. Starting in the second half of the training and continuing in the experimental session, T1 duration was decreased by one frame $(8 \mathrm{~ms})$ after each block if performance was $>85 \%$ and increased by one frame if performance was $<65 \%$. To ensure T1 duration would not deviate too much from the duration of other stimuli, T1 duration was only allowed to be in the range of $42-142 \mathrm{~ms}$ ( $\leq 50 \mathrm{~ms}$ different from other stimuli). The median duration of $\mathrm{T} 1$ in the second session was 125 ms. On $20 \%$ of trials, no T1 was presented and a random distractor letter was presented instead. When both targets were present, T1 predicted which T2 was likely to follow with $75 \%$ accuracy.

We made a few changes to the task design to increase the efficiency of the design. The intertrial interval was reduced to values between 300 and $500 \mathrm{~ms}$. In addition, we asked participants for only one response. They were asked to type in any target letter they had seen during the trial and refrain from typing in a T1 and/or T2 letter when they did not see any. The response was confirmed by pressing the space bar on the keyboard or when a timeout of $4 \mathrm{~s}$ had passed. To further increase the number of trials per condition, we decided to use only Lag 3 (two-thirds of trials) and Lag 10 (one-third of trials). Because T1 duration was staircased on an individual basis, the T1-T2 stimulus-onset asynchrony (SOA) differed between participants. On average, Lag 3 corresponded to an SOA of $308 \mathrm{~ms}$ while Lag 10 corresponded to an SOA of $950 \mathrm{~ms}$.

Finally, we manipulated the instructions we gave to participants to see to what extent explicit knowledge of the relationship between T1 and T2 affected our results. As in Experiment 1, we tested participants during two separate sessions within 1 week. The first group of participants $(N=$ 25) did not receive explicit instructions about the predictive relationships in either session. Thus, their instructions were similar to those given in Experiment 1 . The second group of participants $(N=19)$ received explicit instructions about the T1-T2 relationship at the start of the second session, and a third group of participants $(N=23)$ received those instructions already at the start of their first session.

The first session $(1 \mathrm{~h})$ was used for instructions and training the participants on the task $(10 \times 75$ trials). The experimental session in which participants performed the $\mathrm{AB}$ task lasted $1.5 \mathrm{~h}$ and contained 16 blocks of 75 trials (1200 trials).

Experimental design and statistical analysis: behavioral

Preparatory steps were done with in-house Matlab scripts. Statistical analyses (repeated-measures ANOVAs and paired $t$ tests) were per-

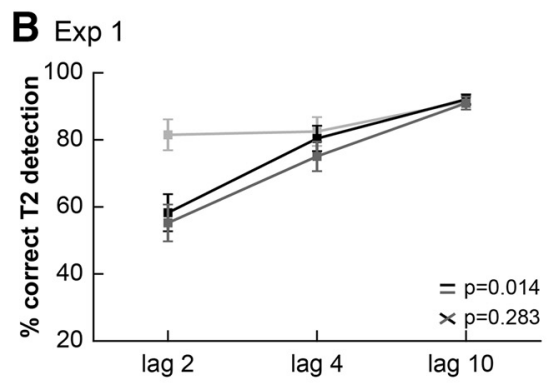

T1-T2 SOA

Exp 1:

lag 2: $183 \mathrm{~ms}$

lag 4: $367 \mathrm{~ms}$

lag 10: $917 \mathrm{~ms}$

Exp 2 (EEG):

lag 3: $275 \mathrm{~ms}$

lag 10: $917 \mathrm{~ms}$

Durations

All stimuli: $92 \mathrm{~ms}$

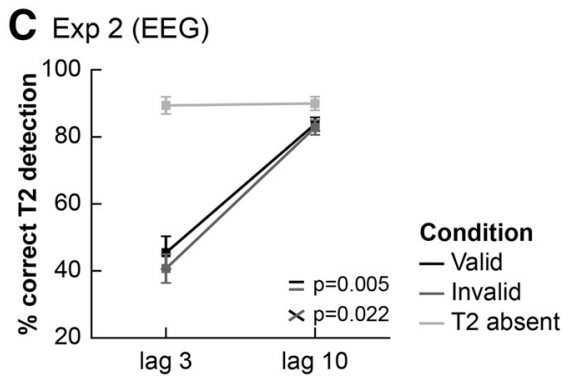


two levels (Lag 3, Lag 10). Percentage correct T2 detection was computed as in Experiment 1 using only the trials on which $\mathrm{T} 1$ was correctly reported. A response was considered correct when the letter a participant entered was the letter that was presented or when a participant refrained from entering a letter when none was presented for the T2-absent trials. In addition, we computed a T2-detection measure to use in a control analysis: if a participant typed in any letter, we categorize the response as a "target seen" response, otherwise we call it a "target absent" response. This outcome measure was used in a control analysis.

Experiment 3. In this experiment, participants gave only one response by typing in the target they had perceived. Trials on which no response was given or on which an impossible response was given (e.g., two T1 targets reported) were excluded from analyses. For T1 and T2 separately, we assessed the accuracy of the responses. The definition of correct and incorrect responses was the same as in Experiment 2 and we also used the same T2-detection measure.

Subsequently, T2 percentage-correct detection was used in a $2 \times 2 \times$ $2 \times 3$ mixed ANOVA with the within-subject factors lag ( $\operatorname{Lag} 3$, Lag 10), expectation (valid, invalid), and $\mathrm{T} 1$ visibility (T1 seen, $\mathrm{T} 1 \mathrm{missed}$ ) and the between-subject factor instruction (none, Start Session 2, Start Session 1). As mentioned before, this between-subject factor was included to find out whether predictive effects would be modulated by explicit knowledge of the relation between T1 and T2. To investigate the effect of T1 visibility in more detail, we followed up the main analyses by other mixed ANOVAs in which we first split up the dataset based on T1 visibility. In situations where we found interactions with the factor instruction, we compared the effects of lag and expectation separately per instruction condition using repeated-measures ANOVAs and pairedsample $t$ tests.

Finally, to test for an interaction between expectation validity and lag, we combined behavioral data from all experiments in a post hoc analysis. Only trials on which T1 was correctly identified were used. For Experiment 1 we averaged data for Lag 2 and Lag 4 to create an average "short lag" condition. Subsequently, these data were entered into a $2 \times 2 \times 3$ mixed ANOVA with the within-subject factors lag (short, long) and expectation (valid, invalid) and the between-subject factor experiment (Experiment 1, Experiment 2, Experiment 3).

\section{EEG measurements}

EEG data were recorded with a BioSemi ActiveTwo system and sampled at $512 \mathrm{~Hz}$ (BioSemi). Potentials were measured from 64 scalp electrodes, along with two reference electrodes on the earlobes and four electrodes measuring horizontal and vertical eye movements. After data acquisition, EEG data were preprocessed with the FieldTrip toolbox for Matlab (Oostenveld et al., 2011; RRID:SCR_004849). First, data were rereferenced to the linked earlobes, high-pass filtered at $0.01 \mathrm{~Hz}$, and epoched from -0.750 to $1 \mathrm{~s}$ surrounding the onset of T2. Data were visually inspected and trials and/or channels containing artifacts not related to eye blinks were manually removed, resulting in deletion of on average $9.1 \%( \pm 3.9 \%)$ of trials and $2.0( \pm 1.7)$ channels. Independent component analysis was used to identify components related to eye blinks or other artifacts that could easily be distinguished from other EEG signals. After the independent component analysis, previously deleted channels were reconstructed based on a nearest neighbor approach. Trials were baseline corrected to the average amplitude before T1 onset $(-0.750$ to $-0.275 \mathrm{~s}$ ). As a final step, we applied a $40 \mathrm{~Hz}$ low-pass filter to the trial data, after which event-related potentials (ERPs) were created separately for each condition of interest.

\section{Experimental design and statistical analysis:} electroencephalography

All EEG analyses are based exclusively on trials where T2 appeared at lag 3 and T1 was correctly identified. We used a combination of Fieldtrip (Oostenveld et al., 2011) and in-house Matlab scripts to perform our analyses. As a first step, we performed cluster-based permutation tests (Maris and Oostenveld, 2007) on the time-window 0-750 ms from stimulus onset to isolate significant ERP events relating to expectation validity (valid, invalid; regardless of T2 visibility) or T2 visibility (seen, missed; regardless of validity) or the interaction between these factors. Next, we used a Matlab script created in-house to isolate the significant events as clusters in time and space. For this purpose, we computed an average difference wave over all channels that were part of the cluster at any point in time. Subsequently, the onset and offset of a cluster were defined as the time period around the maximum difference where the difference did not drop below $50 \%$ of this maximum and where at least one channel showed a significant effect. We then selected the 10 channels that showed the largest effect in this time window. One of the observed events reflected a mixture of the traditionally observed P3a and P3b components (Sergent et al., 2005; Volpe et al., 2007). Therefore, we split the event into two clusters by manually selecting either the 32 most anterior or 32 most posterior EEG channels (from the central midline) before running the cluster-selection procedure.

As an alternative way to establish potential interactions between T2 detection and validity, we inspected in more detail the clusters isolated in the previous step. This may be a more powerful (but also less sensitive) way to detect small effects, because data are averaged over more time points and channels. Within each of the clusters, we performed a $2 \times 2$ repeated-measures ANOVA (and its Bayesian equivalent; see Behavioral analysis) with the factors T2 detection (seen, missed) and expectation validity (valid, invalid) on the cluster data averaged over channels and time. To prevent double dipping, in each analysis we only considered the effects orthogonal to the one used to define the cluster (e.g., not testing the effect of expectation in a cluster defined based on the expectation effect).

\section{Results}

Experiment 1: (how) do expectations affect conscious access? In the first experiment we addressed the question of whether expectations about the likelihood of stimulus identity modulate the likelihood of conscious access and, if so, in what direction. To do so, we used the AB paradigm (Raymond et al., 1992). The AB is an impairment in the conscious perception of the second of two target stimuli presented in rapid succession when the initial target was correctly perceived. Here we modified the paradigm in such a way that the first target ( $\mathrm{T} 1$ : the letter $\mathrm{G}$ or $\mathrm{H}$, in green) predicted which of the second targets would most be likely to appear in case a T2 target was presented (T2: the letter D or K; predicted, $75 \%$; unpredicted, 25\%; in white; Fig. $1 A$ ). On 20\% of trials we presented a random distractor letter instead of a T2 target. At the end of each stream of letters, participants gave three responses. First, they indicated whether they had seen any of the two T2 targets (seen/unseen response). Second, they were prompted to make a forced-choice judgment about the identity of T2 (whether the letter D or K was presented). Third, participants had to make a similar forced-choice decision about the identity of T1 (whether the letter $\mathrm{G}$ or $\mathrm{H}$ was presented; see Materials and Methods). Participants were not explicitly instructed about the predictive relationship between $\mathrm{T} 1$ and $\mathrm{T} 2$.

In Figure 1 we plot the percentage of trials in which T2 was correctly detected and T1 discrimination was also correct (average $\mathrm{T} 1$ accuracy was $94.20 \%$; SD $=5.77 \%$ ) for the three different lags (Lags 2, 4, and 10). T2 was considered detected correctly when participants indicated they saw it (based on the first response) and correctly identified it (based on the second response). Overall, there was a clear $A B$, as reflected by reduced $T 2$ detection when the time (i.e., lag) between T1 and T2 was shorter (Fig. $1 B$; main effect of lag: $\left.F_{(2,48)}=48.15, p<0.001\right)$. Importantly, expectations modulated the T2-detection rate. T2 detection was significantly better when T1 validly predicted T2 (black lines) compared with when the expectation was invalid (gray lines, main effect of validity: $F_{(1,24)}=7.10, p=0.014$; no significant interaction between lag and validity: $\left.F_{(2,48)}=1.30, p=0.283\right)$. These results extend beyond findings of several previous studies (Melloni et al., 2011; Chang et al., 2015; Pinto et al., 2015; Stein 
and Peelen, 2015; Stein et al., 2015) by showing that conscious perception is partly determined by the transitional probability of the input the brain receives.

While these data support the notion that valid expectations trigger access to consciousness, it has been recognized that such findings may not be solely due to changes in perception, but perhaps are also due to changes in decision criteria or response biases (Gayet et al., 2014b; Yang et al., 2014; Attarha and Moore, 2015). To rule out the possibility that our effects could be explained by a response bias in which people simply report the target letter that they expected based on T1, regardless of whether they consciously perceived T2, we performed an analysis with T2 detection (instead of T2 discrimination; see Materials and Methods) as the dependent variable. This analysis takes into account only participants' first response (the seen/ unseen response), regardless of whether the subsequent T2 letter identification was correct. Crucially, this analysis cannot be influenced by any decision/response biases because the response was orthogonal to the participants' expectation. Information about the most likely letter to appear cannot predispose participants to better determine whether a target letter was presented at all. Still, we observed a qualitatively similar pattern of results (main effect of validity: $\left.F_{(1,24)}=5.47, p=0.028\right)$. This finding suggests that validity indeed boosted participants conscious access of T2, instead of merely eliciting a shift in response bias.

\section{Experiment 2: EEG markers of conscious and nonconscious expectation violations}

Subsequently, we tested whether expectation violations can be elicited by nonconsciously processed unpredicted stimuli or whether conscious perception of a stimulus is a prerequisite for it to trigger neural expectation error responses. To test this, we measured subjects' brain activity with EEG while they performed a similar task as in Experiment 1. First, we replicated the behavioral effects of Experiment 1 (Fig. 1C). Overall, T1 performance was high $($ mean $=93.61 \%$; $\mathrm{SD}=7.31 \%)$ and $\mathrm{T} 2$ detection was higher at Lag 10 than at Lag 3 (main effect of lag: $F_{(1,28)}=128.72, p<$ $0.001)$, reflecting a robust $\mathrm{AB}$. More importantly, validly predicted $\mathrm{T} 2 \mathrm{~s}$ were discriminated better than invalidly predicted $\mathrm{T} 2 \mathrm{~s}$ (main effect of validity: $F_{(1,28)}=9.49, p=0.005$ ). The effects were similar in a control analysis where we considered the percentage of T2-seen responses (regardless of the exact letter participants entered), making it less likely that our effect can be explained by a response bias (main effect of validity: $F_{(1,28)}=4.23, p=0.049$ ). In this experiment, the validity effect was significantly modulated by lag (validity $\times$ lag: $F_{(1,28)}=5.86, p=0.022$ ), an effect that was numerically similar, but not significant in Experiment 1. Participants performed better on valid than on invalid trials at Lag 3, but there was no convincing evidence for an effect of expectations at Lag 10 (Lag 3 validity effect: $t_{(28)}=3.40, p=0.002$; Lag 10 validity effect: $\left.t_{(28)}=0.98, p=0.334\right)$. Thus, effects of expectations were larger in the time window in which T2 more often goes unperceived.
Next, we investigated potential differences in the neural processing of predicted and unpredicted stimuli, as a function of stimulus awareness. To this end, we contrasted invalidly and validly predicted T2s and tested this difference using cluster-based permutation testing, correcting for multiple comparisons across both time (0-750 ms) and (electrode) space (Fig. 2; see Materials and Methods; Maris and Oostenveld, 2007). We found one significant difference over frontocentral electrode channels, which reflected greater T2-elicited negativity for invalid compared with valid trials between 174 and $314 \mathrm{~ms}$ ( $p=0.015$; Fig. $2 B$ ), therefore potentially reflecting some type of mismatch response. We then further analyzed this event to test whether the difference was modulated by, or dependent on, conscious perception of T2. Crucially, the size of this frontocentral mismatch component was independent of $\mathrm{T} 2$ awareness $\left(F_{(1,28)}=0.04 ; p=0.850 ; \mathrm{BF}=0.254\right.$; Fig. $2 C$ ), indicating that both seen and unseen $\mathrm{T} 2 \mathrm{~s}$ generated a frontocentral mismatch response.

Additionally, analyses of T2 visibility effects (regardless of expectation validity) replicated previously reported findings (Kranczioch et al., 2003; Sergent et al., 2005; Harris et al., 2013). In these analyses, we examined the difference in ERPs following seen and missed T2s using a cluster-based permutation test (Fig. 3), revealing two significant events. First, a significant negative difference could be observed over (left) posterior electrodes from 170 to 355 ms after T2 onset ( $p=0.010$; Fig. $3 A$ ). This event was followed by a significant long-lasting positive event $(p<0.001)$, reflecting a mixture of the P3a and P3b components, extending over frontal and central electrodes.

Subsequently, we had a closer look at the interactions between conscious access and expectation validity. Therefore, we analyzed in more detail the ERP events isolated in the previous step (Fig. $3 B-G)$. For this analysis we first isolated the traditionally observed $\mathrm{AB}$-related $\mathrm{P} 3 \mathrm{a}$ and $\mathrm{P} 3 \mathrm{~b}$ ERP components from the long- 


\section{A Difference topographies (Seen - Miss)}
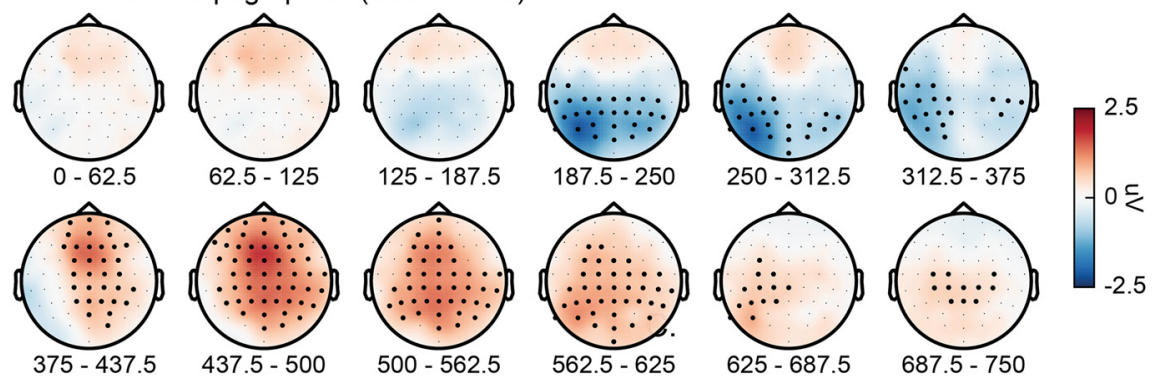

B Early left-posterior negativity
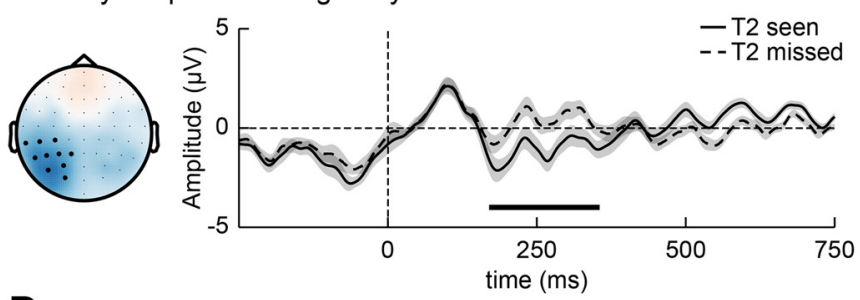

C

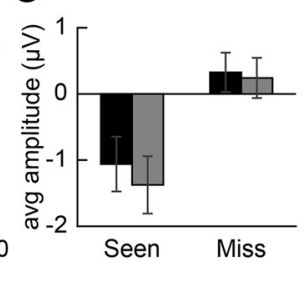

D Anterior positivity (P3a)
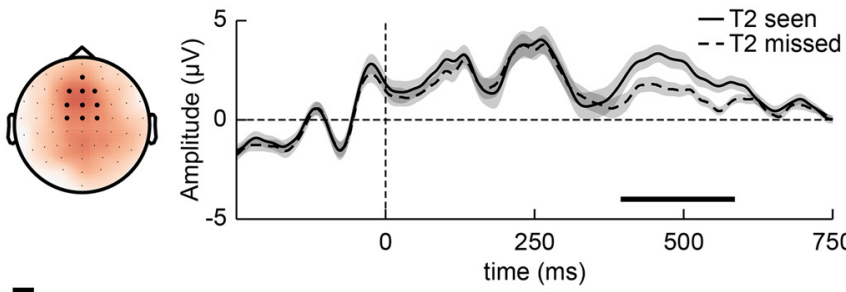

$\mathrm{E}$

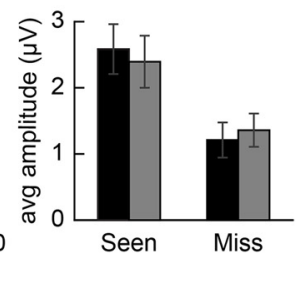

F Posterior positivity (P3b)
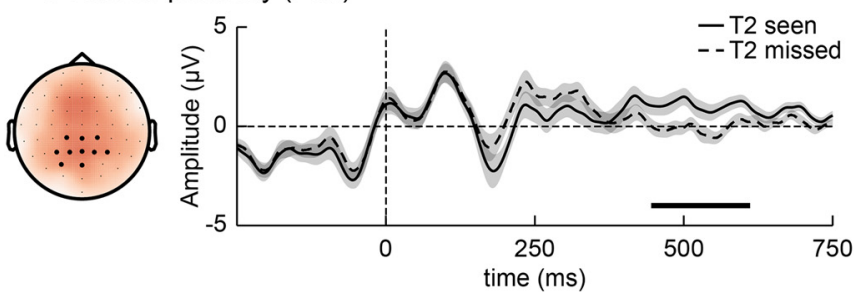

G

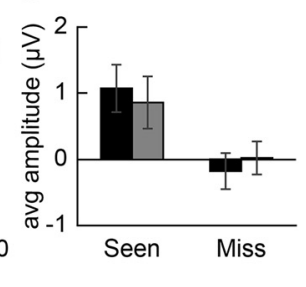

Figure 3. ERP effects related to T2 visibility analyses. $\boldsymbol{A}$, Topographic maps showing the difference between seen and missed T2s over time (0 corresponds to T2 onset). Cluster-based permutation tests were used to isolate the significant events while correcting for multiple comparisons across time and (electrode) space. On each head map, channels showing a significant difference for $\geq 50 \%$ of its time window are highlighted. Three events were isolated based on the permutation tests. $\boldsymbol{B}, \boldsymbol{D}, \boldsymbol{F}$, For each of the events individually, the average ERP time course of the 10 channels shown on the head map on the left, separately for T2-seen and T2-missed conditions is shown. The significant time-window is marked by a black line above the $x$-axis. $\boldsymbol{C}, \boldsymbol{E}, \mathbf{G}, \mathrm{Bar}$ graphs showing the average amplitude of the four conditions (visibility $\times$ prediction) for the significant neural events shown in $\boldsymbol{B}$, $D, F$. In all plots error bars represent SEM.

lasting positive ERP event that differentiated between seen and missed T2s (Sergent et al., 2005). Doing so resulted in an early positive P3a cluster (Fig. 3D) over frontocentral channels that was significant between 395 and $586 \mathrm{~ms}$ and a somewhat later positive P3b cluster (Fig. $3 F$ ) over more posterior parietal channels, which was significant between 445 and 611 ms. Within each of these clusters we performed repeated-measures ANOVAs with the factors validity and $\mathrm{T} 2$ detection. We found no evidence in any of the events that the T2 detection effect was modulated by expectation validity (early left-posterior event: $F_{(1,28)}=0.29 ; p=$ $0.597 ; \mathrm{BF}=0.260$; P3a: $F_{(1,28)}=1.56 ; p=0.222 ; \mathrm{BF}=0.230$; P3b: $\left.F_{(1,28)}=2.10 ; p=0.159 ; \mathrm{BF}=0.296\right)$, though the $\mathrm{BF}$ values suggest that the evidence for the absence of such interactions is moderate at best. This is somewhat surprising, because especially the late positive events have previously been related to conscious access (Sergent et al., 2005; Rutiku et al., 2015) and metacogni-

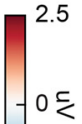

tion (Desender et al., 2016). However, recent investigations show they may reflect cognitive processing at even later stages, merely arising as a consequence of becoming consciously aware of information (Pitts et al., 2014; Silverstein et al., 2015). We did not find evidence that the amplitude of these ERP events was modulated by expectation validity, which may suggest that once a stimulus has been perceived consciously, it is irrelevant whether or not the expectation was valid.

Finally, we directly tested for an interaction between conscious access and expectation by comparing the validity ERP effect (invalid-valid) for T2 seen and T2 missed trials in a cluster-based permutation test (this analysis takes into account the entire scalp topography). Again, no significant interactions between these factors were observed (all cluster $p$ 's $>0.10$ ).

\section{Experiment 3: the role of conscious awareness in implementing top-down expectations}

In our final experiment, we addressed the question of whether expectation formation itself can unfold in the absence of awareness and subsequently influence conscious access (Fig. 4). To address this question, we changed the color of $\mathrm{T} 1$ from green to white and for each subject staircased $\mathrm{T} 1$ duration in such a way that $\mathrm{T} 1$ was correctly identified on $\sim 75 \%$ of the trials (actual T1 identification performance: mean $=76.03 \%$; $\mathrm{SD}=8.65 \%)$. T1 duration did not differ between trials where $\mathrm{T} 2$ was seen and trials where $\mathrm{T} 2$ was missed ( $\mathrm{T} 2$ detection: $t_{(66)}=0.31, p=$ 0.752; $\mathrm{T} 2$ seen: mean $=117.42 \mathrm{~ms}$; $\mathrm{T} 2$ missed: mean $=117.46 \mathrm{~ms}$ ), which indicates that $\mathrm{T} 1$ visibility was not determined by stimulus duration. Likely, internal fluctuations in the system (e.g., variability in attention) must be causing participants to sometimes see $\mathrm{T} 1$ and sometimes miss it. Moreover, on $20 \%$ of trials no T1 was presented (but replaced by a distractor). Further, to test to what extent explicit knowledge of the predictive relationships between stimuli would increase the validity effects, we varied the moment at which explicit information about the predictive relations between $\mathrm{T} 1$ and $\mathrm{T} 2$ was provided. The experiment consisted of a training session and a test session on separate days. A first group of subjects received no explicit instructions about the predictive relations in either session and had to learn them implicitly through experience with the task; the second group received explicit instructions about the T1-T2 relations in the test session only, but not in the first training session; and the third group received explicit instructions already from the start of the experiment.

$\mathrm{T} 1$ visibility strongly affected $\mathrm{T} 2$ detection. When $\mathrm{T} 1$ was seen, $\mathrm{T} 2$ detection was markedly lower than when $\mathrm{T} 1$ was missed (main effect of T1 awareness: $\left.F_{(1,64)}=4.62, p=0.035\right)$, in particular at short lags ( $\mathrm{T} 1$ awareness $\times$ lag: $\left.F_{(1,64)}=72.95, p<0.001\right)$. Validly 
predicted targets were detected more often (main effect of validity: $F_{(1,64)}=33.39$, $p<0.001)$. The effect of expectation validity on $\mathrm{T} 2$ detection varied as a function of $\mathrm{T} 1$ awareness and instructions (T1 awareness $\times$ validity: $F_{(1,64)}=40.55, p<$ 0.001 ; validity $\times$ instruction: $F_{(1,64)}=$ 5.91, $p=0.004$; T1 awareness $\times$ validity $\times$ instruction: $F_{(2,64)}=11.33, p<$ 0.001). When T1 was seen (Fig. 4B), a clear $\mathrm{AB}$ was observed (main effect of lag: $\left.F_{(1,64)}=170.01, p<0.001\right)$ and validly predicted targets were more often detected than invalidly predicted targets (main effect of validity: $F_{(1,64)}=64.97$, $p<0.001$; as in Exps. 1 and 2). Like in the previous experiments, a control analysis considering only the percentage of T2-seen responses (regardless of the exact letter participants entered) also revealed a significant effect of validity (main effect of validity: $\left.F_{(1,64)}=65.83, p<0.001\right)$, making it unlikely that response biases are causing the effect. Interestingly, we also observed a significant $\mathrm{AB}$ for missed $\mathrm{T} 1 \mathrm{~s}$, reflecting a nonconsciously elicited $\mathrm{AB}$ (main effect of lag: $\left.F_{(1,64)}=74.42, p<0.001\right)$. This $\mathrm{AB}$ effect cannot be explained by an overall T2-detection performance benefit for targets presented later in the trial because the $\mathrm{AB}$ was larger for trials on which $\mathrm{T} 1$ was presented but missed compared with trials on which no T1 was presented in the trial (lag $\times$ T1 presence: $\left.F_{(1,66)}=24.19, p<0.001\right)$. However, although missed $\mathrm{T} 1 \mathrm{~s}$ triggered an $\mathrm{AB}$, expectation validity did not affect T2-detection performance for missed T1s (main effect of validity: $\left.F_{(1,64)}=0.35, p=0.554\right)$, regardless of the type of instruction participants received about the predictive relation between T1 and T2 (validity $\times$ instruction: $F_{(2,64)}=0.64, p=$ 0.533 ). A Bayesian equivalent of the repeated-measures analysis strongly suggested validity should not be included in a model of the data $(\mathrm{BF}=0.084)$.

The above results highlight that only when $\mathrm{T} 1$ was seen, valid expectations facilitated T2 detection. A post hoc analysis on T1seen trials only revealed that this effect was modulated by how explicitly we instructed participants about the predictive relationship between $\mathrm{T} 1$ and $\mathrm{T} 2$ (validity $\times$ instruction: $F_{(2,64)}=$ $14.83, p<0.001)$. The validity effect, as defined by the difference between valid and invalid trials, averaged across the two lags, increased with more explicit instructions (Group 1: 1.87\%; Group 2: 19.53\%; Group 3: 26.27\%). These results indicate that, not only does the visibility of $\mathrm{T} 1$ define the predictive impact on T2 detection, but also the extent to which these predictive relations are explicitly known affects the impact of expectations on conscious access. This may also explain why the validity effect appeared more pronounced in Experiment 3 than in Experiments 1 and 2: in Experiments 1 and 2 subjects were not explicitly instructed about the predictive relations between $\mathrm{T} 1$ and $\mathrm{T} 2$.

Finally, in contrast to Experiment 2, on T1-seen trials the validity effect was independent of lag (validity $\times$ lag: $F_{(1,64)}=$ $1.750, p=0.191)$. Since we anticipated stronger expectation effects at short lags, behavioral data from all three experiments was combined in a post hoc analysis. Only trials on which T1 was correctly identified were used and for Experiment 1 we averaged

\section{B Exp 3: T1 seen}

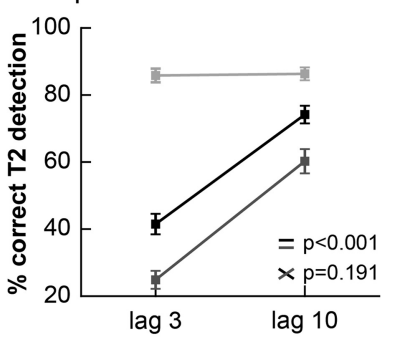

T1-T2 SOA C Exp 3: T1 missed / absent lag 3: $\pm 308 \mathrm{~ms}$

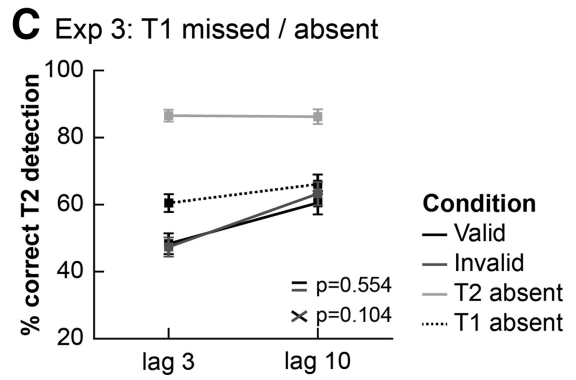

Durations

T1: 42-142 ms T2 \& distractors: $92 \mathrm{~ms}$

Figure 4. Task design and behavioral results of Experiment 3.A, Trial structure of the task used in Experiment 3. T1 visibility was reported (T1 seen). As in Experiments 1 and 2, when T1 was seen, validly predicted T2s were more often detected than invalidly not enhance $T 2$ detection. However, a missed $\mathrm{T} 1$ still triggered a significant $\mathrm{AB}$, compared with trials on which no $\mathrm{T} 1$ was presented

data for Lag 2 and Lag 4 to create an average "short lag" condition. A significant interaction between validity and lag showed that across all experiments, the expectation effect was stronger at short lags compared with the long lags (validity $\times$ lag: $F_{(1,118)}=$ 5.73, $p=0.018$; no validity $\times$ lag $\times$ experiment interaction: $\left.F_{(2,118)}=0.065, p=0.937\right)$.

\section{Discussion}

In this report we investigated three important questions regarding the intricate relationship between top-down expectations and conscious awareness. The first question that we addressed was how prior information about the identity of an upcoming stimulus influences the likelihood of that stimulus entering conscious awareness. Using a novel AB paradigm in which the identity of T1 cued the likelihood of the identity of T2, we showed that stimuli that confirm our expectation have a higher likelihood of gaining access to conscious awareness than stimuli that violate our expectations, especially at short lags. The expectation effect was qualitatively similar across all three experiments, regardless of subtle experimental differences in task design and overall performance between those experiments. Furthermore, it could not be explained by simple shifts in the response criterion, because it was also present for a dependent measure orthogonal to the expectation manipulation. Together, this suggests that valid expectations amplify the perceptual strength of a stimulus and therefore increase the chance of conscious access, possibly due to the sharpening of its neural representations (Kok et al., 2012). This interpretation is supported by previous experiments that have shown varying effects of expectations on (subjective) perception, such as studies showing that prior knowledge increases the speed (Melloni et al., 2011; Chang et al., 2015; Pinto et al., 2015; De Loof et al., 2016) and accuracy (Stein and Peelen, 2015) of stimulus detection. Furthermore, our findings complement recent studies showing that 
the $\mathrm{AB}$ can be reduced when there is knowledge about temporal statistics of the task (Lasaponara et al., 2015; Visser et al., 2015) or when the latency of T2 targets is explicitly cued (Martens and Johnson, 2005; Nieuwenstein et al., 2005). In addition, two recent reports have shown that when attention is diverted, in some subjects expecting the presentation of a stimulus can elicit an illusory stimulus percept even though no stimulus is presented. (Mack et al., 2016; Aru and Bachmann, 2017). Future experimentation is required to shed light on the generalizability of our effect to simpler tasks. Such experiments may also consider using other measures of subjective perception (e.g., perceptual awareness scale; Overgaard et al., 2006).

The second question we addressed was related to the extent to which nonconscious stimuli can trigger prediction error responses, as measured with EEG. Over the last 20 years, we and others have shown that nonconscious information processing is rather sophisticated (Dehaene and Changeux, 2011; van Gaal and Lamme, 2012), and that a diverse range of high-level cognitive processes can unfold nonconsciously (Dehaene et al., 2001; Custers and Aarts, 2005; Lau and Passingham, 2007; Pessiglione et al., 2007, 2008, van Gaal et al., 2010, 2012, 2014). Interestingly, in Experiment 2 we found that expectations violated by a nonconscious stimulus trigger a stronger negative frontocentral ERP component than expectations that are confirmed. This neural event was similar for trials on which T2 was seen and on trials where T2 was missed, highlighting that conscious awareness of a stimulus is not a prerequisite for it to trigger a prediction error response (Mathews et al., 2014; Malekshahi et al., 2016). This effect may reflect a mismatch signal, similar to the MMN (Näätänen et al., 2007), which is a negative deflection following oddball stimuli that develops 100-200 ms after stimulus onset. Sometimes this effect lasts longer, in some experiments until $\sim 400 \mathrm{~ms}$, depending on the specifics of the task and stimulus material (Pöppel, 2004; Stefanics et al., 2011; Kimura and Takeda, 2015). While in terms of interpretation this effect is similar to a mismatch effect, its topography is slightly different than a typical visually evoked MMN, which generally peaks more posteriorly, although considerable variation in its topography has been reported (Pöppel, 2004). Alternatively, it is possible that the higher activation for valid compared with invalid trials corresponds to the frontal selection positivity, which is a well known marker of nonspatial attentional processes (Kenemans et al., 1993). In our paradigm, this could be explained as improved attentional selection when expectations are confirmed. Although the exact nature of the observed component deserves future experimentation, the key finding is that the effect was independent of $\mathrm{T} 2$ perception and purely depends on the validity of the expectation. This is in line with studies that have shown context influences on nonconscious information processing $(\mathrm{Na}-$ kamura et al., 2007; Van Opstal et al., 2011; Gayet et al., 2014a; Rohaut et al., 2016), studies that have shown that the MMN can be observed when the expectation violations are unattended (Bekinschtein et al., 2009; Stefanics et al., 2011; King et al., 2013; Dykstra and Gutschalk, 2015; Kimura and Takeda, 2015), and more generally evidence for relatively high-level processing of nonconscious stimuli (Luck et al., 1996; van Gaal and Lamme, 2012; Silverstein et al., 2015). Nevertheless, the absence of interactions in the ERP is also somewhat surprising (but see Rutiku et al., 2016), because as noted earlier such interactions between expectation validity and conscious $\mathrm{T} 2$ detection were present in behavior. A neural basis for this effect should exist, but may be very subtle. Recently, a study by Aru et al. (2016) found early $(<100 \mathrm{~ms})$ differences in signal amplitude over posterior channels that predicted the behavioral benefit of prior knowledge on the detection of stimuli presented at the threshold of perception. Another potentially interesting signature to investigate could be the onset of components related to conscious perception (Melloni et al., 2011) and how they relate to expectations. Moreover, it is possible that instead of signal strength, it is the signal-to-noise ratio or sharpness of the representation that is improved (Kok et al., 2012). Possibly, valid expectations do not modulate the amplitude of the neural response, but instead increase the specificity of the neural representation.

In the final experiment, we showed that conscious perception of T1, initiating the expectation, is a prerequisite for influences on conscious access to occur. In the subset of trials where subjects did not see T1, there was no expectation effect on T2-detection performance. This result contrasts with findings from a recent study that suggested that some priors may operate nonconsciously (Chang et al., 2016). Chang and colleagues presented participants with masked gray-scale natural scene images and found that the nonconscious processing of these images improved subsequent recognition of their degraded counterparts, so-called "Mooney images," presented seconds later. One explanation for this difference is that the priors on which the effects of Chang et al. relied may be more automatic and hard-wired than the relatively arbitrary relationships that people must learn and actively use in our experiments. It is possible that lower-level, automatic expectations are more easily processed outside of awareness compared with the more active ones studied here.

Further, it is also possible that with more training we would find nonconscious expectation effects. However, since subjects were already trained on the task on a separate day before performing the experimental session, this possibility seems unlikely. We did observe greater validity effects when subjects were made explicitly aware of the predictive nature of $\mathrm{T} 1$, suggesting that explicit knowledge of stimulus associations can facilitate the effects of stimulus-induced expectations. Finally, it should be noted that we did not test the full range of timing intervals between $\mathrm{T} 1$ and T2. It has been shown and proposed that the processing of nonconscious stimuli is relatively fleeting (Greenwald et al., 1996; Dehaene et al., 2006; but see King et al., 2016), so it is conceivable that the T1-T2 lags that we have used here may have been too long to observe expectation effects triggered by unseen T1s. Nevertheless a significant $\mathrm{AB}$ was observed on trials on which $\mathrm{T} 1$ was missed, indicating that attention was still captured by a missed $\mathrm{T} 1$ at the T1-T2 lags used here. This latter result is in line with evidence showing that nonconscious stimuli are able to trigger attentional capture (Ansorge et al., 2009; Mulckhuyse and Theeuwes, 2010; Hsieh et al., 2011) and with a study showing lower T2 detection for T1s that were missed compared with trials without a T1 [in that experiment this effect was independent of lag (Nieuwenstein et al., 2009)].

In summary, three main conclusions can be drawn from the present series of studies. First, expectation confirmation, compared with violation, increases the likelihood of conscious awareness, suggesting that valid expectations amplify the perceptual strength of a stimulus. Second, nonconscious violations of conscious expectations are registered in the human brain. Third, expectations need to be implemented consciously to subsequently modulate conscious access. These results suggest a differential role of conscious awareness in the hierarchy of predictive processing, in which the active implementation of top-down expectations requires conscious awareness, whereas a conscious expectation and a nonconscious stimulus can interact to generate prediction errors. How these nonconscious prediction errors are 
used for updating future behavior and shaping trial-by-trial learning is a matter for future experimentation.

\section{References}

Ansorge U, Kiss M, Eimer M (2009) Goal-driven attentional capture by invisible colors: evidence from event-related potentials. Psychon Bull Rev 16:648-653. CrossRef Medline

Aru J, Bachmann T (2017) Expectation creates something out of nothing: the role of attention in iconic memory reconsidered. Conscious Cogn 53:203-210. CrossRef Medline

Aru J, Rutiku R, Wibral M, Singer W, Melloni L (2016) Early effects of previous experience on conscious perception. Neurosci Conscious 1:niw004. CrossRef

Attarha M, Moore CM (2015) Onset rivalry: factors that succeed and fail to bias selection. Atten Percept Psychophys 77:520-535. CrossRef Medline

Bar M (2004) Visual objects in context. Nat Rev Neurosci 5:617-629. CrossRef Medline

Bar M (2009) Predictions: a universal principle in the operation of the human brain. Philos Trans R Soc Lond B Biol Sci 364:1181-1182. CrossRef Medline

Bar M, Kassam KS, Ghuman AS, Boshyan J, Schmid AM, Schmidt AM, Dale AM, Hämäläinen MS, Marinkovic K, Schacter DL, Rosen BR, Halgren E (2006) Top-down facilitation of visual recognition. Proc Natl Acad Sci U S A 103:449-454. CrossRef Medline

Bekinschtein TA, Dehaene S, Rohaut B, Tadel F, Cohen L, Naccache L (2009) Neural signature of the conscious processing of auditory regularities. Proc Natl Acad Sci U S A 106:1672-1677. CrossRef Medline

Brainard DH (1997) The psychophysics toolbox. Spat Vis 10:433-436. CrossRef Medline

Chang AY, Kanai R, Seth AK (2015) Cross-modal prediction changes the timing of conscious access during the motion-induced blindness. Conscious Cogn 31:139-147. CrossRef Medline

Chang R, Baria AT, Flounders MW, He BJ (2016) Unconsciously elicited perceptual prior. Neurosci Conscious 2016:niw008. CrossRef Medline

Clark A (2013) Whatever next? predictive brains, situated agents, and the future of cognitive science. Behav Brain Sci 36:181-204. CrossRef Medline

Custers R, Aarts H (2005) Positive affect as implicit motivator: on the nonconscious operation of behavioral goals. J Pers Soc Psychol 89:129-142. CrossRef Medline

Dehaene S, Changeux JP (2011) Experimental and theoretical approaches to conscious processing. Neuron 70:200-227. CrossRef Medline

Dehaene S, Naccache L, Cohen L, Bihan DL, Mangin JF, Poline JB, Rivière D (2001) Cerebral mechanisms of word masking and unconscious repetition priming. Nat Neurosci 4:752-758. CrossRef Medline

Dehaene S, Changeux JP, Naccache L, Sackur J, Sergent C (2006) Conscious, preconscious, and subliminal processing: a testable taxonomy. Trends Cogn Sci 10:204-211. CrossRef Medline

De Loof E, Van Opstal F, Verguts T (2016) Predictive information speeds up visual awareness in an individuation task by modulating threshold setting, not processing efficiency. Vision Res 121:104-112. CrossRef Medline

Denison R, Piazza E, Silver M (2011) Predictive context biases perceptual selection during binocular rivalry. J Vis 11:312. CrossRef

Desender K, Van Opstal F, Hughes G, Van den Bussche E (2016) The temporal dynamics of metacognition: dissociating task-related activity from later metacognitive processes. Neuropsychologia 82:54-64. CrossRef Medline

Dykstra AR, Gutschalk A (2015) Does the mismatch negativity operate on a consciously accessible memory trace? Sci Adv 1:e1500677. CrossRef Medline

Friston K (2005) A theory of cortical responses. Philos Trans R Soc Lond B Biol Sci 360:815-836. CrossRef Medline

Garrido MI, Kilner JM, Stephan KE, Friston KJ (2009) The mismatch negativity: a review of underlying mechanisms. Clin Neurophysiol 120:453463. CrossRef Medline

Gayet S, Van der Stigchel S, Paffen CL (2014a) Seeing is believing: utilization of subliminal symbols requires a visible relevant context. Atten Percept Psychophys 76:489-507. CrossRef Medline

Gayet S, Van der Stigchel S, Paffen CL (2014b) Breaking continuous flash suppression: competing for consciousness on the pre-semantic battlefield. Front Psychol 5:460. CrossRef Medline

Greenwald AG, Draine SC, Abrams RL (1996) Three cognitive markers for unconscious semantic activation. Science 273:1699-1702. CrossRef Medline
Gregory RL (1980) Perceptions as hypotheses. Philos Trans R Soc Lond B Biol Sci 290:181-197. CrossRef Medline

Harris JA, McMahon AR, Woldorff MG (2013) Disruption of visual awareness during the attentional blink is reflected by selective disruption of late-stage neural processing. J Cogn Neurosci 25:1863-1874. CrossRef Medline

Hohwy J (2012) Attention and conscious perception in the hypothesis testing brain. Front Psychol 3:96. CrossRef Medline

Hsieh PJ, Colas JT, Kanwisher N (2011) Pop-out without awareness. Psychol Sci 22:1220-1226. CrossRef Medline

Jeffreys H (1967) Theory of probability, 3rd ed. Oxford: Oxford UP.

Kenemans JL, Kok A, Smulders FT (1993) Event-related potentials to conjunctions of spatial frequency and orientation as a function of stimulus parameters and response requirements. Electroencephalogr Clin Neurophysiol 88:51-63. CrossRef Medline

Kimura M, Takeda Y (2015) Automatic prediction regarding the next state of a visual object: electrophysiological indicators of prediction match and mismatch. Brain Res 1626:31-44. CrossRef Medline

King JR, Faugeras F, Gramfort A, Schurger A, El Karoui I, Sitt JD, Rohaut B, Wacongne C, Labyt E, Bekinschtein T, Cohen L, Naccache L, Dehaene S (2013) Single-trial decoding of auditory novelty responses facilitates the detection of residual consciousness. Neuroimage 83:726-738. CrossRef Medline

King JR, Pescetelli N, Dehaene S (2016) Brain mechanisms underlying the brief maintenance of seen and unseen sensory information. Neuron 92: 1122-1134. CrossRef Medline

Koelsch S, Heinke W, Sammler D, Olthoff D (2006) Auditory processing during deep propofol sedation and recovery from unconsciousness. Clin Neurophysiol 117:1746-1759. CrossRef Medline

Kok P, Jehee JF, de Lange FP (2012) Less is more: expectation sharpens representations in the primary visual cortex. Neuron 75:265-270. CrossRef Medline

Kranczioch C, Debener S, Engel AK (2003) Event-related potential correlates of the attentional blink phenomenon. Cogn Brain Res 17:177-187. CrossRef Medline

Lamme VA, Roelfsema PR (2000) The distinct modes of vision offered by feedforward and recurrent processing. Trends Neurosci 23:571-579. CrossRef Medline

Lasaponara S, Dragone A, Lecce F, Di Russo F, Doricchi F (2015) The "serendipitous brain": low expectancy and timing uncertainty of conscious events improve awareness of unconscious ones (evidence from the attentional blink). Cortex 71:15-33. CrossRef Medline

Lau HC, Passingham RE (2007) Unconscious activation of the cognitive control system in the human prefrontal cortex. J Neurosci 27:5805-5811. CrossRef Medline

Love J, Selker R, Marsman M, Jamil T, Dropmann D, Verhagen AJ, Ly A, Gronau QF, Smira M, Epskamp S, Matzke D, Wild A, Knight P, Rouder JN, Morey RD, Wagenmakers E-J (2015) JASP [computer software].

Luck SJ, Vogel EK, Shapiro KL (1996) Word meanings can be accessed but not reported during the attentional blink. Nature 383:616-618. CrossRef Medline

Mack A, Erol M, Clarke J, Bert J (2016) No iconic memory without attention. Conscious Cogn 40:1-8. CrossRef Medline

Malekshahi R, Seth A, Papanikolaou A, Mathews Z, Birbaumer N, Verschure PF, Caria A (2016) Differential neural mechanisms for early and late prediction error detection. Sci Rep 6:24350. CrossRef Medline

Maris E, Oostenveld R (2007) Nonparametric statistical testing of EEG- and MEG-data. J Neurosci Methods 164:177-190. CrossRef Medline

Martens S, Johnson A (2005) Timing attention: cuing target onset interval attenuates the attentional blink. Mem Cognit 33:234-240. CrossRef Medline

Mathews Z, Cetnarski R, Verschure PF (2014) Visual anticipation biases conscious decision making but not bottom-up visual processing. Front Psychol 5:1443. CrossRef Medline

Melloni L, Schwiedrzik CM, Müller N, Rodriguez E, Singer W (2011) Expectations change the signatures and timing of electrophysiological correlates of perceptual awareness. J Neurosci 31:1386-1396. CrossRef Medline

Mulckhuyse M, Theeuwes J (2010) Unconscious attentional orienting to exogenous cues: a review of the literature. Acta Psychol (Amst) 134:299309. CrossRef Medline

Näätänen R, Tervaniemi M, Sussman E, Paavilainen P, Winkler I (2001) "Primitive intelligence" in the auditory cortex. Trends Neurosci 24:283288. CrossRef Medline 
Näätänen R, Paavilainen P, Rinne T, Alho K (2007) The mismatch negativity (MMN) in basic research of central auditory processing: a review. Clin Neurophysiol 118:2544-2590. CrossRef Medline

Nakamura K, Dehaene S, Jobert A, Le Bihan D, Kouider S (2007) Taskspecific change of unconscious neural priming in the cerebral language network. Proc Natl Acad Sci U S A 104:19643-19648. CrossRef Medline

Nieuwenstein MR, Chun MM, van der Lubbe RH, Hooge IT (2005) Delayed attentional engagement in the attentional blink. J Exp Psychol Hum Percept Perform 31:1463-1475. CrossRef Medline

Nieuwenstein M, Van der Burg E, Theeuwes J, Wyble B, Potter M (2009) Temporal constraints on conscious vision: on the ubiquitous nature of the attentional blink. J Vis 9(9):18.1-14. CrossRef Medline

Oostenveld R, Fries P, Maris E, Schoffelen JM (2011) FieldTrip: open source software for advanced analysis of MEG, EEG, and invasive electrophysiological data. Comput Intell Neurosci 2011:156869. CrossRef Medline

Overgaard M, Rote J, Mouridsen K, Ramsøy TZ (2006) Is conscious perception gradual or dichotomous? A comparison of report methodologies during a visual task. Conscious Cogn 15:700-708. CrossRef Medline

Panichello MF, Cheung OS, Bar M (2012) Predictive feedback and conscious visual experience. Front Psychol 3:620. CrossRef Medline

Pessiglione M, Schmidt L, Draganski B, Kalisch R, Lau H, Dolan RJ, Frith CD (2007) How the brain translates money into force: a neuroimaging study of subliminal motivation. Science 316:904-906. CrossRef Medline

Pessiglione M, Petrovic P, Daunizeau J, Palminteri S, Dolan RJ, Frith CD (2008) Subliminal instrumental conditioning demonstrated in the human brain. Neuron 59:561-567. CrossRef Medline

Pinto Y, Gaal V, de Lange FP, Lamme VAF, Seth AK (2015) Expectations accelerate entry of visual stimuli into awareness. J Vis 15(8):13. CrossRef Medline

Pitts MA, Padwal J, Fennelly D, Martínez A, Hillyard SA (2014) Gamma band activity and the P3 reflect post-perceptual processes, not visual awareness. Neuroimage 101:337-350. CrossRef Medline

Pöppel E (2004) Lost in time: a historical frame, elementary processing units and the 3-second window. Acta Neurobiol Exp (Wars) 64:295-301. Medline

Ratcliff R, McKoon G (2008) The diffusion decision model: theory and data for two-choice decision tasks. Neural Comput 20:873-922. CrossRef Medline

Raymond JE, Shapiro KL, Arnell KM (1992) Temporary suppression of visual processing in an RSVP task: an attentional blink? J Exp Psychol Hum Percept Perform 18:849-860. CrossRef Medline

Rohaut B, Alario F-X, Meadow J, Cohen L, Naccache L (2016) Unconscious semantic processing of polysemous words is not automatic. Neurosci Conscious 2016:niw010. CrossRef

Rouder JN, Morey RD, Speckman PL, Province JM (2012) Default Bayes factors for ANOVA designs. J Math Psychol 56:356-374. CrossRef

Rouder JN, Morey RD, Verhagen J, Swagman AR, Wagenmakers EJ (2017) Bayesian analysis of factorial designs. Psychol Methods 22:304-321. CrossRef Medline

Ruby P, Caclin A, Boulet S, Delpuech C, Morlet D (2008) Odd sound processing in the sleeping brain. J Cogn Neurosci 20:296-311. CrossRef Medline

Rutiku R, Martin M, Bachmann T, Aru J (2015) Does the P300 reflect conscious perception or its consequences? Neuroscience 298:180-189. CrossRef Medline
Rutiku R, Tulver K, Aru J, Bachmann T (2016) Visual masking with frontally applied pre-stimulus TMS and its subject-specific neural correlates. Brain Res 1642:136-145. CrossRef Medline

Sergent C, Baillet S, Dehaene S (2005) Timing of the brain events underlying access to consciousness during the attentional blink. Nat Neurosci 8:13911400. CrossRef Medline

Silverstein BH, Snodgrass M, Shevrin H, Kushwaha R (2015) P3b, consciousness, and complex unconscious processing. Cortex 73:216-227. CrossRef Medline

Stefanics G, Kimura M, Czigler I (2011) Visual mismatch negativity reveals automatic detection of sequential regularity violation. Front Hum Neurosci 5:46. CrossRef Medline

Stefanics G, Kremláček J, Czigler I (2016) Mismatch negativity and neural adaptation: two sides of the same coin. response: commentary: visual mismatch negativity: a predictive coding view. Front Hum Neurosci 10: 13. CrossRef Medline

Stein T, Peelen MV (2015) Content-specific expectations enhance stimulus detectability by increasing perceptual sensitivity. J Exp Psychol Gen 144: 1089-1104. CrossRef Medline

Stein T, Kaiser D, Peelen MV (2015) Interobject grouping facilitates visual awareness. J Vis 15(8):10. CrossRef Medline

Strauss M, Sitt JD, King JR, Elbaz M, Azizi L, Buiatti M, Naccache L, van Wassenhove V, Dehaene S (2015) Disruption of hierarchical predictive coding during sleep. Proc Natl Acad Sci U S A 112:E1353-E1362. CrossRef Medline

Summerfield C, de Lange FP (2014) Expectation in perceptual decision making: neural and computational mechanisms. Nat Rev Neurosci 15: 745-756. CrossRef Medline

van Gaal S, Lamme VA (2012) Unconscious high-level information processing. Neuroscientist 18:287-301. CrossRef Medline

van Gaal S, Lamme VA, Ridderinkhof KR (2010) Unconsciously triggered conflict adaptation. PLoS One 5:e11508. CrossRef Medline

van Gaal S, de Lange FP, Cohen MX (2012) The role of consciousness in cognitive control and decision making. Front Hum Neurosci 6:121. CrossRef Medline

van Gaal S, Naccache L, Meuwese JD, van Loon AM, Leighton AH, Cohen L, Dehaene S (2014) Can the meaning of multiple words be integrated unconsciously? Philos Trans R Soc Lond B Biol Sci 369:2013021220130212. CrossRef Medline

Van Opstal F, Calderon CB, Gevers W, Verguts T (2011) Setting the stage subliminally: unconscious context effects. Conscious Cogn 20:1860-1864. CrossRef Medline

Visser TA, Ohan JL, Enns JT (2015) Temporal cues derived from statistical patterns can overcome resource limitations in the attentional blink. Atten Percept Psychophys 77:1585-1595. CrossRef Medline

Volpe U, Mucci A, Bucci P, Merlotti E, Galderisi S, Maj M (2007) The cortical generators of P3a and P3b: a LORETA study. Brain Res Bull 73:220 230. CrossRef Medline

Yang E, Brascamp J, Kang MS, Blake R (2014) On the use of continuous flash suppression for the study of visual processing outside of awareness. Front Psychol 5:724. CrossRef Medline 